\title{
Progress in \\ Neutron Capture Therapy \\ for Cancer
}




\section{Progress in \\ Neutron Capture Therapy \\ for Cancer}

Edited by

Barry J. Allen

Australian Nuclear Science and Technology Organisation

Menai, New South Wales, Australia

Douglas E. Moore

University of Sydney

Sydney, New South Wales, Australia

and

Baiba V. Harrington

Australian Nuclear Science and Technology Organisation

Menai, New South Wales, Australia 


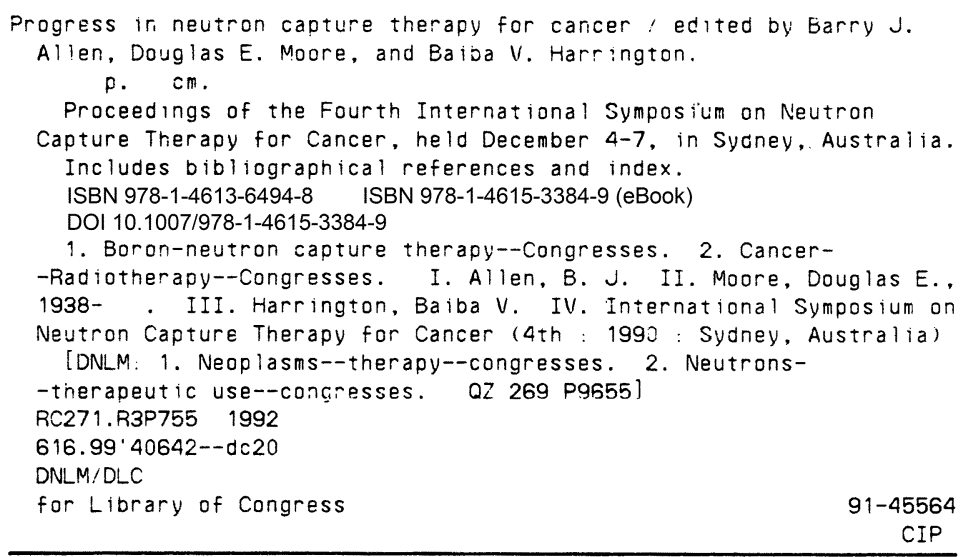

Proceedings of the Fourth International Symposium on Neutron Capture Therapy for Cancer, held December 4-7, 1990, in Sydney, Australia

ISBN 978-1-4613-6494-8

(C) 1992 Springer Science+Business Media New York Originally published by Plenum Press, New York in 1992 Softcover reprint of the hardcover 1st edition 1992

All rights reserved

No part of this book may be reproduced, stored in a retrieval system, or transmitted in any form or by any means, electronic, mechanical, photocopying, microfilming, recording, or otherwise, without written permission from the Publisher 


\section{SYMPOSIOM ORGANISATION AND SPONSORS}

HOSTS :

International Society for Neutron Capture Therapy Australian Nuclear Science \& Technology Organisation The University of Sydney

AUSPICES : International Union Against Cancer (UICC)

SPONSORS:

Australian Cancer Society

Sydney Melanoma Foundation

Australian Nuclear Science \& Technology Organisation

Qantas

Ansett

General Atomics

Energy Resources Australia

Peter MacCallum Cancer Institute

U.S. Department of Energy

Department of Industry, Technology and Commerce

Callery Chemical Company 
Barry Allen - Chair, Ansto

Baiba Harrington - Physics, Ansto

Gerald Wilson - Chemistry, Ansto

Douglas Moore - Analysis, University of Sydney

Roger Martin - Radiobiology, Peter MacCallum Cancer Institute

David Barkla - Preclinical, Monash University

Hedy Mameghan - Clinical, Prince of Wales Hospital 


\section{NATIONAL ADVISORY COMMITTEE}

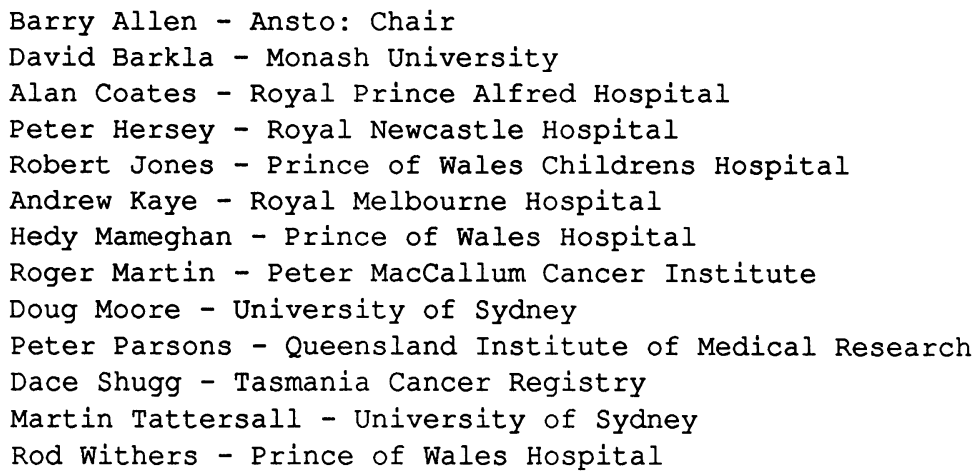

\section{INTERNATIONAL ADVISORY COMMITTEE}

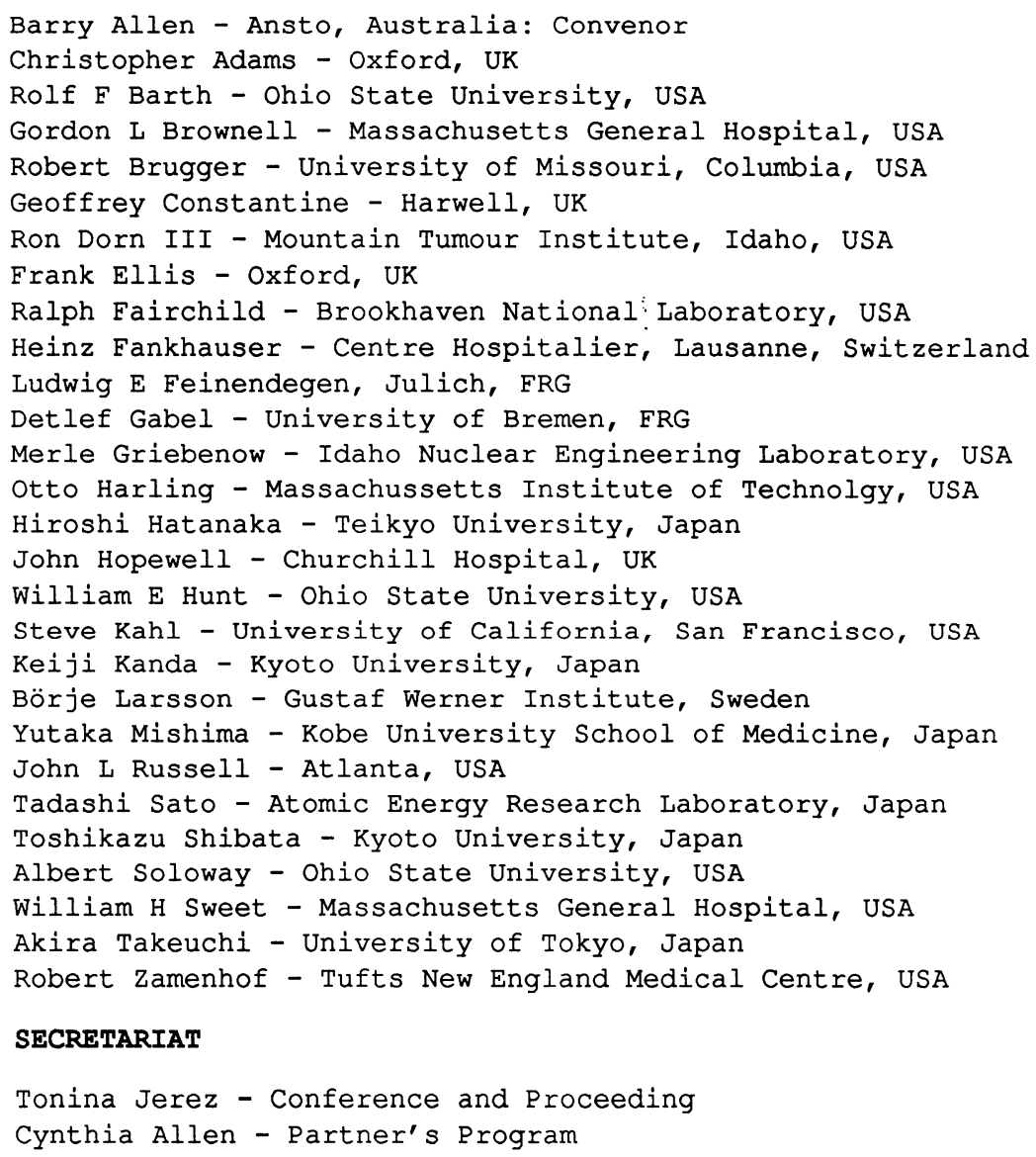




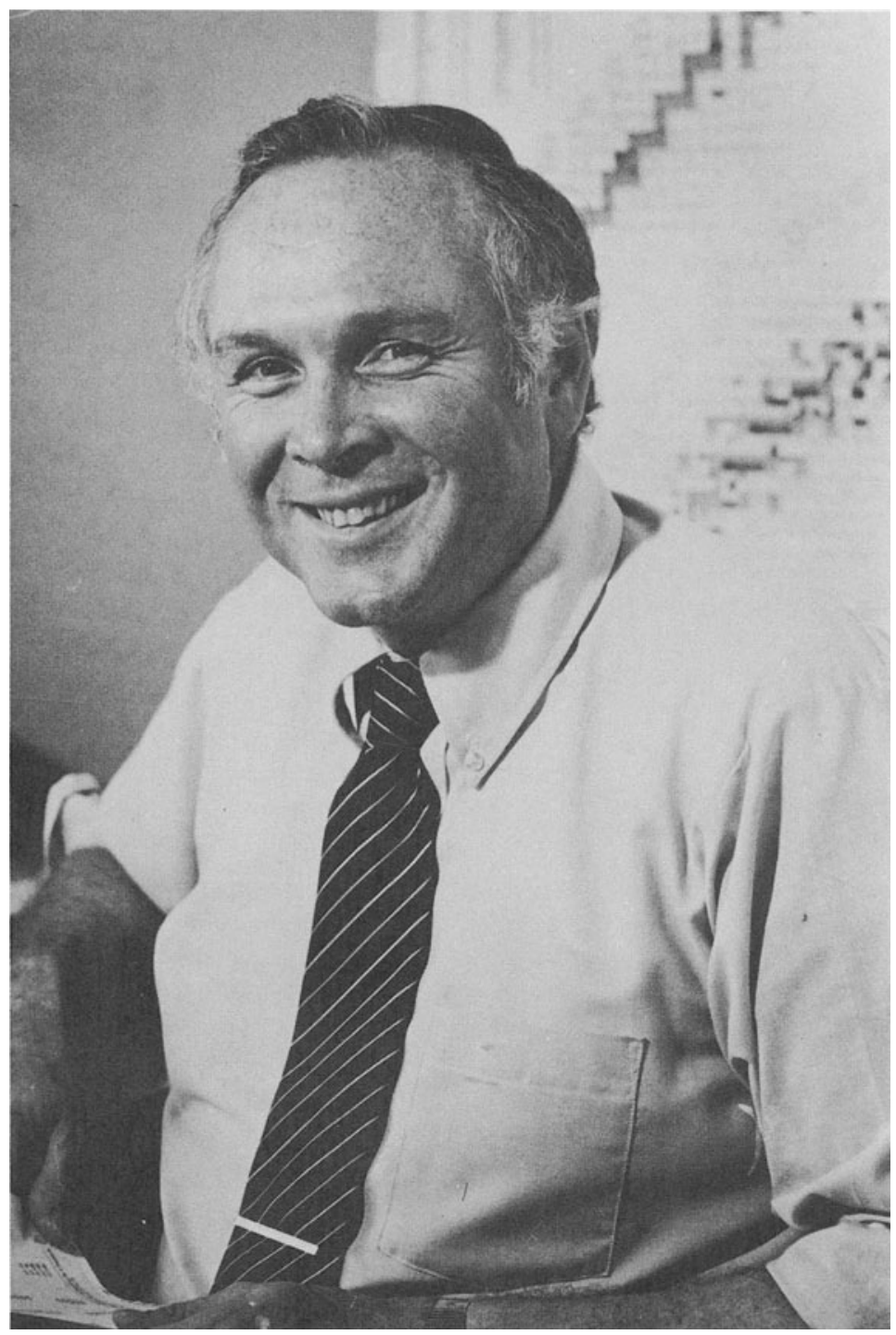

RALPH GRANDISON FAIRCHILD

(1935-1990)

Boron Neutron Capture Therapy lost a powerful advocate and contributor with the premature and untimely passing of Ralph G. Fairchild on December 18, 1990. The impact was particularly severe because he had just attended the Fourth International Symposium on Neutron Capture Therapy where he was an active participant in most of the sessions and other functions.

Ralph graduated with a B.S. in Physics from St. Lawrence University in 1958, and M.S. in Nuclear Engineering from Cornell University in 1961, and a Ph.D. from Adelphi University in 1975. He began his affiliation with Brookhaven National Laboratory in 1961 as a Medical Physicist in the Medical Department and it was then that he began his BNCT-related 
experimentation with foresight and determination. In 1965, Ralph initiated experiments on an epithermal neutron beam which, by allowing deeper penetration in tissue, overcame a principal problem associated with the use of thermal neutrons. Thus, more than any other scientist in the United States, he kept the possibility of BNCT alive during some very lean decades.

He was the first to describe the physical dosimetry and radiobiological characteristics of californium-252 brachytherapy sources. Additionally, he contributed to the development of ${ }^{125}$ I plaques for the treatment of ocular melanoma. He evaluated numerous melanaffinic agents for their utility in the treatment of malignant melanoma, and identified radiolabelled thouracil as one of the most significant biomolecules for use in both diagnosis and therapy.

Fairchild was a firm believer that cancer radiotherapy would best be improved through the utilization of binary systems involving the exploitation of the cell's own physiological requirements to permit the uptake of various biomolecules carrying target atoms, followed by the activation of these atoms with radiation. In addition to BNCT, Ralph postulated Photon Activation Therapy (PAT) as another binary system for the treatment of malignant brain tumours. In a theoretical paper in 1982, he proposed the use of iododeoxyuridine (IdUrd) incorporated in tumour cell DNA and its subsequent activation with photons above the $K$ absorption edge of iodine to induce a photoelectric effect and concomitant Auger cascades. He identified samarium-145 as the isotope with the most suitable energy for inducing this effect, and proposed the interstitial implantation of these radioactive sources via brachytherapy techniques. Initial clinical trials with PAT are currently underway at the Ohio State University.

Many of us who have had the privilege of knowing Ralph well will remember the unusual and admirable qualities that he possessed. In addition to a wonderful sense of humour, his quiet, humble, gentle and unassuming manner concealed an intense energy and drive for work. His deep-thinking and incisive mind, coupled with curiosity, a keen power of observation for scientific facts and a genuine love for science distinguished his person. His enthusiasm was infectious. Many of Ralph Fairchild's activities were given unselfishly to the interest of others, to colleagues in science, to teaching, and to his research collaborators.

He has been recognized internationally by his collaborators as the undisputed leader in the field of BNCT. He has been referred to as the intellectual glue which bonded the efforts of BNCT investigators throughout America. His collaborators describe him as open minded, honest, self-critical and, more importantly, as someone who was sincerely and genuinely interested in each of their research endeavours. Ralph's breadth of knowledge was always available for others to utilize. Working with him meant not only a symbiotic relationship, but a synergistic one as well.

He will always be remembered as a good friend, an excellent and dedicated scientist, and as the leading contributor to the scientific body of knowledge in the field of Neutron Capture Therapy. He has spawned a generation of friends and scientists to whom he has given the task of carrying out his dream.

Victor P. Bond

Brookhaven National Laboratory 


\section{PREFACE}

Despite the many advances made in the diagnosis and therapy of cancer, the mortality rate is still about half that of the incidence rate. However, the odds are not evenly distributed. Prognosis for some cancers is good, but for others, few patients will survive 12 months. This latter group of cancers is characterised by a proclivity to disseminate malignant cells in the host organ. The degree of surgery possible may be limited by the critical nature of the organ, and chemotherapy and radiotherapy are of palliative value only. In some cases systemic metastases occur, but in other cases, failure to achieve local control results in death. First among these cancers are the high grade brain tumours, astrocytoma 3,4 and glioblastoma multiforme. Local control of these tumours should lead to cure. Other cancers melanoma metastatic to the brain, for which a useful palliative therapy is not yet available, and pancreatic cancer for which localised control at an early stage could bring about improved prognosis. Patients with these cancers have little grounds for hope. Our primary objective is to reverse this situation with Neutron Capture Therapy (NCT). The purpose of this fourth symposium is to hasten the day whereby patients with these cancers can reasonably hope for substantial remissions.

The first symposium on NCT was held in Boston in 1983, followed by Tokyo in 1985 and Bremen, Germany in 1988. A tradition of multidisciplinary papers presented in plenary sessions has been established and is continued in this symposium. Indeed many members of the International Advisory Committee were particularly emphatic about this feature. It is the multidisciplinary nature of NCT that sets this field somewhat apart from other research areas.

The rapid growth in activity in NCT in recent years is mirrored by the large number of submitted abstracts for this symposium. Over 150 participants from the USA, Japan, Europe and Australia presented more than 160 papers on aspects of physics, chemistry, biology and clinical oncology in Neutron Capture Therapy. For the first time it was necessary to introduce both parallel and poster sessions. The International Union Against Cancer (UICC) granted auspices to the symposium, which was held at the University of Sydney.

All papers published in these proceedings have been subject to review by at least two referees, and in many cases the papers have been substantially revised by the authors. In some cases controversy over results or interpretation remains, and must be resolved by further research. In other cases, the reviewing has been tempered because of the restricted page allocation, submission deadlines and requirements for balanced reporting. After all, these are conference proceedings and completeness is an important issue. These proceedings therefore represent a snapshot of NCT research around the world. 


\section{Binary Therapies}

The binary therapy concept is one new approach whereby enhanced tumour specificity is achieved by the synergistic action of two different modalities. One example is photodynamic therapy, where a laser beam activates a non-toxic photosensitive compound to create a local chemical toxicity. This is being investigated in the intraoperative treatment of high grade brain tumours and some other cancers. However, this method is restricted by the limited penetration of the laser light through tissue. Another example is NCT, where non-toxic boron compounds are taken up by cancer cells and the boron is subsequently activated in situ by an incident neutron beam, causing a nuclear reaction with energy release being localised to the target and nearest neighbour cells. Thus individual cancer cells can be killed in the midst of normal cells with minimal damage to the host tissue if boron is selectively taken up by the cancer cells.

The implementation of this procedure is not necessarily straightforward but, as illustrated by many papers presented at the symposium, much progress has been made in recent years. Of particular interest were papers describing the new epithermal neutron beams, the rapidly growing European Collaboration and the extensive Washington State University (WSU) dog studies.

Animal studies show that NCT can achieve local control of melanoma xenografts in nude mice, brain tumours in rats, ocular melanoma in rabbits, spontaneous brain tumours in dogs and cutaneous melanoma and glioblastoma in human patients. These results and their significance are considered in more detail in the following discussion.

Thermal NCT for glioblastoma

To date, over 100 high-grade brain tumour patients have been treated by intra-operative NCT by Prof Hiroshi Hatanaka in Japan. The open tumour bed is irradiated by a thermal neutron beam after intracarotid injection of borocaptate (BSH). With the exception of grade 3,4 tumours in the cerebral mantle, 5-year patient survival is comparable to Hatanaka's own conventional treatment series, which in turn is similar to that obtained at other centres, ie 2-3\% survival at 5 years. However, a dramatic difference is observed for tumours within $6 \mathrm{~cm}$ of the cortical surface. For the 12 patients in this group, seven have survived to 5 years. Only in this group has the weakly penetrating thermal neutron beam delivered an adequate dose to the deeper region of the tumour.

Since about one third of grade 3,4 gliomas occur in the cerebral mantle, a randomised trial of NCT seems warranted on the basis of Hatanaka's results.

\section{Thermal NCT for subcutaneous melanoma}

The Kobe group, led by Prof Yutaka Mishima, has pioneered the use of boronophenylalanine (BPA) in the treatment of subcutaneous melanoma by NCT. For these cases, the thermal neutron beam is ideal, as the maximum dose is at the surface. Yet, skin effects are limited to erythema and dry desquamation because of the low uptake of BPA by the skin. Complete local eradication of subungual or acral lentiginous melanoma has been achieved in 5 cases. 
An epithermal neutron beam which can penetrate up to $10-\mathrm{cm}$ depth is required to treat deep-seated lesions with NCT. Epithermal beams are now available at BNL and Massachusetts Institute of Technology (MIT) in the US, under test at the Joint Research Council (JRC) reactor at Petten in The Netherlands and under consideration at the Idaho National Engineering Laboratory, US and Ansto in Australia. These beams would potentially allow treatment of high grade brain tumours by fractionated bilateral irradiations of the head. The therapeutic ratio is the dose to the tumour relative to the maximum dose to normal tissue. Values of 2-3 for this ratio could be achieved across the whole brain if boron concentrations of $30 \mathrm{ppm}$ are obtained in the tumour concomitantly with $3 \mathrm{ppm}$ in normal tissue.

\section{Epithermal NCT in a spontaneous dog brain tumour model}

Dogs with naturally occurring cerebral tumours have been irradiated with epithermal neutrons at the BNL reactor after intravenous administration of BSH. Blood boron concentration was about $25 \mathrm{ppm}$ during the irradiation and tumour to blood ratios were less than one. However tumour to normal brain tissue ratios range up to 15 . Nine dogs with contrast enhancing lesions in CT scans were treated by NCT with detailed post-treatment examinations. Some dogs have now survived in excess of 12 months.

\section{Ocular melanoma in rabbits}

An ocular melanoma model in the rabbit has been developed at BNL, where Dr Jeff Coderre has demonstrated complete eradication of the implanted melanoma in 10 of $13 \mathrm{NCT}$ cases for an estimated therapeutic ratio of 3 . A BPA slurry was digested by the rabbits prior to thermal neutron irradiation of the eye. Cataracts developed in all cases.

\section{Rat Glioma model}

Two reports of complete control of implanted brain tumours in the rat glioma model also came from BNL. Using BPA, Coderre demonstrated long term survival (150 days) in 7 of 16 rats with no survivors in the thermal neutron control group (i.e no BPA injection) or unirradiated groups. Dr Darryl Joel used the disulfide dodecaborane dimer with continuous tail-vein infusion over 3 days, followed by neutron irradiation of the implanted intracerebral gliosarcoma in rats. Untreated rats had a median post-inoculation survival of 21 days, the boron free neutron controls survived 26 days, and rats treated by NCT survived 60 days. Two of 12 animals lived more than one year. At a higher neutron dose, 6 of 10 animals remain alive more than 10 months after NCT.

\section{Melanoma xenografts in nude mice}

In the subcutaneous melanoma xenograft model, tumour growth rather than survival is the endpoint as subcutaneous melanomas in this model are not of themselves lethal. Harding-Passey melanoma cells were injected subcutaneously in the thigh of nude mice. Two weeks later the mice received an intraperitoneal injection of $B P A$, the melanomas were irradiated with thermal neutrons and the subsequent growth rate monitored and compared with the boron free neutrons group and unirradiated controls. Dr Barry Allen of Ansto reported local control in 6 of 8 mice over 300 days, whereas only a 3 week growth delay was observed in mice treated by neutron irradiation alone. 
These results, together with the pharmacokinetic data now available for many different models, including patients, demonstrate the potential value of NCT. Nevertheless, the inability to achieve therapeutic boron concentrations in all cancer cells is the probable cause of the failure to achieve complete local control.

\section{Research Awards}

On behalf of the symposium sponsors, awards were made to scientists on the basis of their research contributions to the conference. Members of the executive board of the International Society for NCT and the organising Committees were excluded. The Australian Cancer Society Award went to $\mathrm{Dr}$ Heinz Fankhauser, a neurosurgeon from Switzerland, for his study of the uptake of borocaptate sodium in brain tumour patients prior to surgery. These studies are providing the essential information needed to determine absorbed dose for clinical trials. The second recipient was Dr Pat Gavin, Veterinarian, Washington State University, for his extensive studies of the pharmacokinetics of borocaptate sodium in dogs with naturally occurring tumours and for demonstrating the efficacy of NCT in this animal model.

The Sydney Melanoma Foundation Award was presented to Dr Jeff Coderre, Brookhaven National Laboratory, for the successful treatment of ocular melanoma in rabbits by NCT.

The Callery Chemical Company Award went to Dr Stephen Kahl, a boron chemist from the University of California San Francisco and Dr John Hill, University of Melbourne, for the synthesis of the boron-porphyrin compound BOPP and the demonstration of highly specific uptakes by glioma cells in the rat brain glioma model. Tumour to normal brain tissue ratios of 300:1 were observed, and BOPP was detected in individual glioma cells separated from the tumour. This class of compound suggests a role for photodynamic therapy as an adjunct to NCT.

The General Atomics Award went to Dr Floyd Wheeler, of the Idaho National Engineering Laboratory, for studies of the physics of filtered neutron beams and dosimetry, while Prof Hiroshi Fukuda from Tohoku University received the Energy Resources of Australia Award for studies of normal tissue tolerance to NCT.

\section{Round Table Debate}

A feature of the symposium was the round table debate between Australian cancer specialists and a panel of international experts in NCT. The role of NCT in the control of locally incurable cancer was identified, but caution was urged with regard to clinical trials. NCT was regarded as a knife, albeit exceptionally sharp, and demonstration of the value of improved local control rather than cure should be the goal.

The need to eliminate every clonogenic cell was discussed. Whether this would ever be achievable by NCT is by no means certain. Boron is taken up in varying amounts by cells, depending on many factors such as tumour morphology and cell metabolism. Statistically, if the cell concentrations of boron were uniform, a very small number of cells would still be free of neutron capture reactions. Yet there is ample evidence in many models that tumours can be eradicated by NCT. Small tumours take up boron compounds more readily than larger tumours which have hypoxic and necrotic regions; cell killing by NCT may therefore be more efficacious in the former. However, standard external beam radiotherapy also fails to kill every clonogenic cell, and the question to be answered, ultimately by clinical trials, is whether NCT can do a better job. 


\section{Clinical Trials}

Although more experimental work needs to be done the question of when to commence further clinical trials was considered. Current therapy for high grade brain tumours is palliative only, and a trial would soon determine if NCT was advantageous. However, the risk to the future of NCT was thought to take precedence over premature clinical trials which, if deemed a failure, might also impede further development in the field. Should trials be delayed until more highly tumour specific boroncontaining porphyrins are tested and approved for use? This was not the consensus. Current compounds are expected to give therapeutic ratios of 2-3 across the brain and this is more than enough to investigate efficacy. Nonetheless, vigorous development of new boron chemicals should continue.

Should NCT be incorporated into a radiotherapy protocol? This would be a safe way to introduce NCT, by replacing 5 fractions of radiotherapy with one NCT exposure. However, large numbers of patients might be required to discern a significant improvement in prognosis.

Is an experimental therapy a better choice for patients than therapy known to be of limited benefit for most patients? We do know how to limit dose to normal tissue so toxicity to normal tissues should not be worse than that achieved with conventional therapy. Should Hatanaka's results for cerebral mantle tumours be confirmed in the forthcoming epithermal beam trials for brain tumours at all sites, then a major advance in the treatment of these cancers would have been achieved. But even without the Hatanaka data, the results reported at the Fourth Symposium provide strong and independent support for the potential of NCT to improve control in localised tumours with poor prognoses.

Barry J. Allen

President, International Society for Neutron Capture Therapy, 1988-1990 


\section{OPENING ADDRESS}

Two years ago at the third international symposium on Neutron Capture Therapy in Bremen, Detlef Gabel related the fable of the four musicians of Bremen. These were the donkey, dog, cat and rooster. The musicians received little recognition until they played in concert. By analogy, the physicist, chemist, biologist and clinician must work together to overcome incurable cancer by NCT.

Now long ago in the dreamtime of the Australian aborigine, this problem was foreseen and solved. Unlike the European solution, where three placental animals must play to the tune of the rooster, the Australian solution was to invent the platypus.

The platypus is like the physicist, as busy as a beaver; in fact it has the tail of a beaver. It is also like the chemist because it synthesizes toxic chemicals for the venom in the spur of each hind leg. But it is the biologist's nightmare. The platypus lays eggs but suckles its young in a make-shift pouch. Moreover, it has a single ovary and is a monotreme, both very bird like properties. Finally, the platypus is noted for its bill, as is the clinician. This bill is both tough and electro-sensitive. Maybe it could take Mastercard too!

Thus the uniquely Australian solution is to combine all the requirements of the Bremen quartet into a singlet. Where many countries combine in Europe to form an NCT team, and many laboratories in the USA and Japan compete for NCT funds, in Australia it is Lucas Heights, with its Moata and HIFAR reactors, which is the natural centre to coordinate the first phase of NCT.

This symposium brings together the Bremen musicians, the Japanese crane, the great American bison and the Australian platypus. This week we shall all play in concert for the progress of NCT and the betterment of mankind.

Barry J. Allen

Convener, Fourth Internationaj. Symposium on Neutron Capture Therapy for Cancer 


\section{THE UNITED STATES DEPARTMENT OF ENERGY PROGRAM IN NEUTRON CAPTURE THERAPY}

First, I would like to thank Dr Allen and his associates for having made the splendid arrangements for the symposium.

The United States involvement in Neutron Capture Therapy began in the 1950 's as a cooperative program between the Brookhaven National Laboratory, the Massachusetts General Hospital and the Massachusetts Institute of Technology (MIT). Drs Sweet and Brownell, who were the prime movers in those studies, are present at this symposium.

The first clinical trials were performed at the Brookhaven Graphite reactor using a thermal neutron beam with B-10 sodium tetraborate or B-10 sodium pentaborate. Later, the Medical Research Reactor and the MIT reactor became available for these studies. The early clinical results, however, were disappointing, and the efforts shifted from clinical trials to more basic studies directed to finding alternative compounds and to improvement of the neutron beam. These studies continued at a rather modest level for many years during which it was recognized that an epithermal rather than a thermal neutron beam would be needed to provide the penetration required for treating the dee per lesions, and Dr Soloway, who is also among those present today, the BSH compound (mercapto undecahydrododecaborate) that has been used in most of the more recent studies.

The clinical trials conducted by Dr Hatanaka in Japan have used the BSH compound. Dr Hatanaka's promising results stimulated a revival of interest in neutron capture therapy, and the support for work in this field has increased considerably. The Department of Energy currently supports work related to neutron capture therapy at the Idaho National Engineering Laboratory, Brookhaven National Laboratory, Ohio State University, the State University of New York at Stony Brook, the Massachusetts General Hospital, the Massachusetts Institute of Technology, Tufts-New England Medical Centre, and the University of Tennessee. Speakers representing these institutions will be presenting details of the program. With the very recent increased funding provided by Congress for the conversion of the Power Burst Facility at the Idaho National Engineering Laboratory, it can be expected that efforts in neutron capture therapy will continue to expand. We are of course deeply interested in the progress that is being made in other countries, and look forward to hearing about your plans and developments during this week's meetings.

Again, thanks to Dr Allen and his associates for the tremendous effort they have put into making this symposium possible.

James S. Robertson

United States Department of Energy 
CONTENTS

\section{PROJECTS REVIETS}

An Optimised EpiThermal Neutron Beam for Neutron

Capture Therapy (NCT) at the Brookhaven

Medical Research Reactor (BMRR)

R G Fairchild, V Benary, J Kalef-Ezra, S K Saraf,

R M Brugger, A Shih, R A Gahbauer, J H Goodman,

B H Laster, J Gajewski, E B Ramsay, L E Reinstein,

$S$ Fiarman, $Y$ Kamen

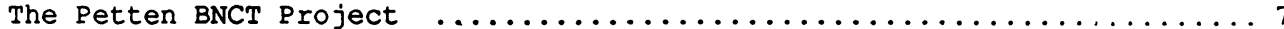

R L Moss, F Stecher-Rasmussen, R Huiskamp,

I Dewit, B Mijnheer

The Idaho Power Burst Facility/Boron Neutron

Capture Therapy (PBE/BNCT) Program Overview ...............13

R V Dorn III, M L Griebenow, A L Ackermann,

L G Miller, P R Gavin, D L Miller,

F J Wheeler, K M Bradshaw, T I Richards,

D E Wessol, Y D Harker, D W Nigg, P D Randolph,

W $\mathrm{F}$ Bauer

The Neutron Capture Therapy Research Program at New England Medical Centre and the Massachusetts

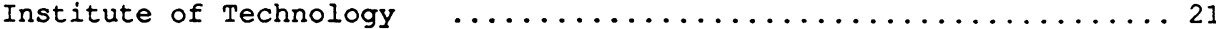

R Zamenhof, H Madoc-Jones, O Harling, D Wazer, S Saris, J Yanch, G Solares, G. Rogers

NCT Program at the University of Missouri-Columbia

R M Brugger, J A Shih, H S Wu, H B Liu, X S Luo

Goals of the European collaboration on Boron Neutron

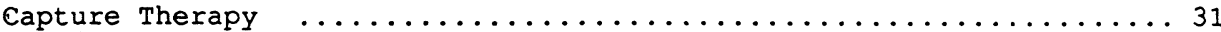

D Gabel

Critique of MIT 1989 Workshop on Neutron Beam Design, Development, and Performance for Neutron Capture

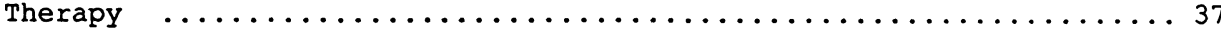

O K Harling, J A Bernard, R G Zamenhof

Program for BNCT with Accelerator-Produced keV Neutrons

and Related Chemical and Biological Studies

A Andersson, J Andersson, J-O Burgman, J Capala,

J Carlsson, H Condé, J Crawford, S Graffmann,

E Grusell, A Holmberg, E Johansson, B S Larsson,

B Larsson, T Liljefors, P Lindström, J Malmquist,

L Pellettieri, O Pettersson, J Pontén, A Roberti,

K Russel, H Reist, I Salford, S Sjöberg,

B Stenerlöw, P Strömberg, B Westermark 
Performance of the Currently Available Epithermal Neutron Beam at the Massachusetts Institute of Technology Research Reactor (MITR-II)

J R Choi, R G Zamenhof, J C Yanch, R Rogus, O K Harling

A Compact TRIG Reactor for Boron Neutron Capture

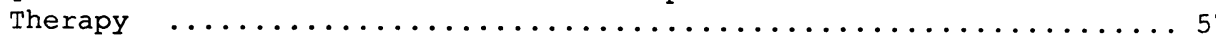

W I Whittemore

Design, Construction and Installation of an Epithermal Neutron Beam for BNCT at the High Flux Reactor, Petten ........63

R L Moss, F Stecher-Rasmussen, K Ravensberg, G Constantine $P$ Watkins

Modelling an Epithermal Neutron Beam for a DIDO type Reactor Using MCNP - a Monte Carlo code

D Ross, G Constantine, D R Weaver

MCNP Calculations for the Design and Characterisation of the Petten BNCT Epithermal Neutron Beam

P Watkins, G Constantine, F Stecher-Rasmussen, W Freudenreich, R L Moss, R Ricchena

Monte Carlo Calculation Results for the Epithermal Neutron Beam at the Brookhaven Medical Reactor ............75

J Gajewski, E B Ramsay, L E Reinstein, S Saraf, R Fairchild

Design Considerations for the Proposed HIFAR Thermal and Epithermal Neutron Capture Therapy

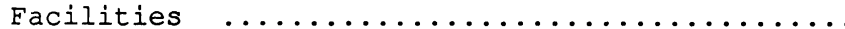

G J Storr, B J Allen, B V Harrington, L R Davis, M M Elcombe, $\mathrm{H}$ Meriaty

Neutron Beam Parameters on LVR-15 Reactor for Neutron

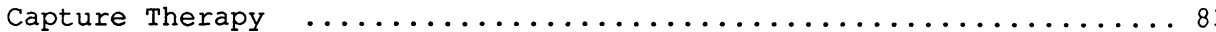

J Burian, M Marek, J Rataj

Study on the Best Design of Neutron Irradiation Facility

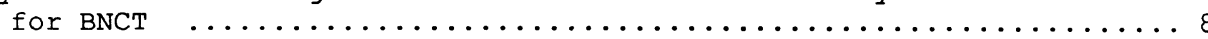

O. Aizawa, H Yamada

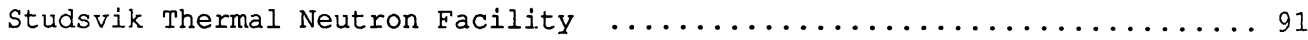

O Pettersson, P Svensson, B Larsson, E Grusell

Effective Thermal Neutron Collimation for Neutron Capture Therapy Using Neutron Absorption and Scattering Reactions .......................... 95

T Kobayashi, S Fujihara, K Kanda

Reevaluation of Thermal Neutron Field of the KUR Heavy Water Facility for Biomedical Uses (optimisation of bismuth, heavy water and graphite

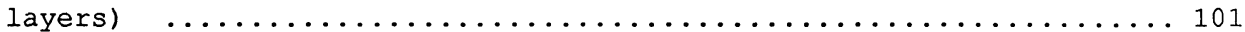

Y Sakurai, S Fujihara, T Kobayashi, K Kanda

\section{ACCELERATOR NEUTRON SOURCES}

Design of an Accelerator-Based Epithermal Neutron Beam for Boron Neutron Capture Therapy .................... 107

J C Yanch, X-L Zhou, RE Shefer, R E Klinkowstein, G L Brownell 
An Integrated Neutronic and Thermal-Hydraulic Design Study for an Accelerator Neutron Irradiation Facility ............ 113

T E Blue, T-X B Qu, R N Christensen, P Guo, J W Blue

An Epithermal Neutron Source for BNCT Using a Tandem

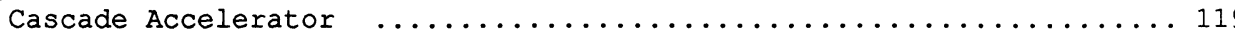

R E Shefer, R E Klinkowstein, J C Yanch, G L Brownell

Accelerator Based Neutron Sources for Neutron Capture

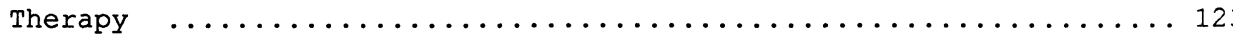

E Grusell

Neutrons for Capture Therapy Produced by $72 \mathrm{MeV}$ protons

J F Crawford, $\mathrm{H}$ Reist, $\mathrm{H}$ Conde, K Elmgren, T Ronnqvist,

E Grusell, B Nilsson, O Pettersson, P Stromberg, B Larsson

\section{DOSIMETRY AND TREATMIENT PLANNING}

A Monte Carlo Study of Ideal Beams for Epithermal Neutron

Beam Development For Boron Neutron Capture Therapy .......... 133

$\mathrm{J}$ C Yanch, O K Harling

Analytical Dosimetry for Spontaneous Tumor Dogs

receiving Boron Neutron Capture Therapy

$\mathrm{F} J$ Wheeler, C A Atkinson, P R Gavin

Some Physical Factors Influencing the Distributions of Thermal Neutrons and Gamma Rays in a Phantom

$\mathrm{T}$ Matsumoto

Characterisation of the BMRR and PBF Epithermal-Neutron Beams in Phantom Using Three-Dimensional Deterministic Radiation Transport Theory $\ldots \ldots \ldots \ldots \ldots \ldots \ldots$

D W Nigg, F J Wheeler, P D Randolph

Beyond the Epithermal-Neutron Beam: The Analytical

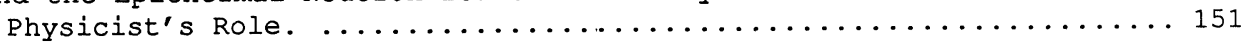

F $J$ Wheeler, D W Nigg, D E Wessol

Measurements of Lineal Energy Spectra for Neutron Capture Therapy Using a Boron Doped LET Chamber

H I Amols, C S Wuu, S Saraf, P Kliauga, L E Reinstein

Dose Measurements and Calculations in the Epithermal Neutron Beam at the Brookhaven Medical Research Reactor (BMRR)

V Benary, R G Fairchild, J Kalef-Ezra, D Greenberg, $Y$ Kamen, S Fiarmen, L Wielopolski

Review of Techniques Developed at Harwell Laboratory for Neutron and Gamma-Ray Characterisation of Filtered Neutron Beams for Boron Neutron Capture

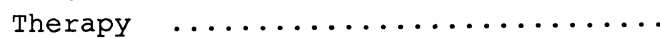

C A Perks, G Constantine, $\mathrm{H} \mathrm{J}$ Delafield

Relation Between Tolerance Dose of $\mathrm{Skin}$ and ${ }^{10} \mathrm{~B}$ Concentration in Neutron Capture Therapy for

T Kobayashi, K Kanda, Y Ujeno, H Fukuda, K Ando, Y Mishima, M Ichihashi, J Hiratsuka.

Treatment Planning for Neutron Capture Therapy of Glioblastoma Multiforme Using an Epithermal Neutron Beam from the MITR-II Research Reactor

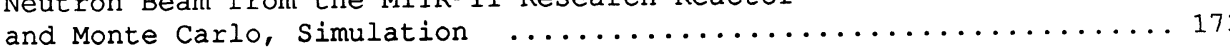

$R$ Zamenhof, J Brenner, J Yanch, D Wazer, H Madoc-Jones, S Saris, O Harling 
Enhancement of Tumour Dose by the Gadolinium Neutron Capture Reaction in Cf-252 Brachytherapy

$\mathrm{J}$ Wierzbicki, Y Maruyama, R Martin

Gadolinium as a Neutron Capture Therapy Agent

J A Shih, R M Brugger

Boron Neutron Capture Enhancement in Cf-252 Brachytherapy

$\mathrm{J}$ Wierzbicki, Y Maruyama, C Alexander

Comparison of Dose Distributions With Boron-10 Augmented Sources of ${ }^{252} \mathrm{Cf}$ obtained by Monte Carlo Simulation

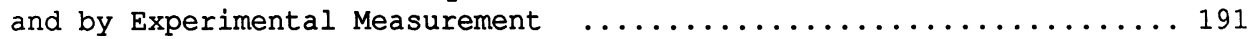

J C Yanch, R G Zamenhof, J Wierzbicki, Y Maruyama

Boron Neutron Capture Enhancement of the Tumor Dose in

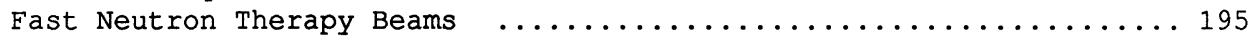

P Wootton, R Risler, J Livesey, S Brossard, G Laramore, T Griffin

Neutron Capture Reactions in a $\mathrm{d}(14)+$ Be Fast Neutron Beam

W Sauerwein, I Heselmann, F Pöller, J Rassow, H Szypniewski, C Streffer, H Sack

The Potential of Internal Neutron Sources in Capture Therapy ....... 203 J F Crawford

\section{BORON CHEMISTRY - GENERAL}

Carboranyl Precursors of Nucleic Acids - Potential

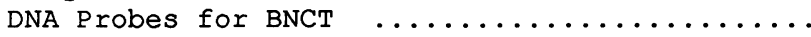

A H Soloway, A K M Anisuzzaman, L Liu, R F Barth, F Alam, W Tjarks

Boron Containing Nucleic Acids

B F Spielvogel, A Sood, B R Shaw, I H Hall,

R G Fairchild, B H Laster, C Gordon

Preparation of New Boron Compounds With Potential for Application in ${ }^{10} \mathrm{~B}$ NCT: Derivatives of

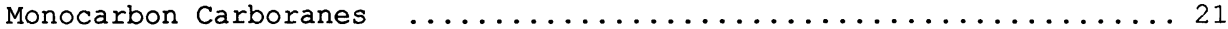

J H Morris, S-A Khan, F Mair, G Peters

Molecular Design and Synthesis of ${ }^{10} \mathrm{~B}$ Carriers for

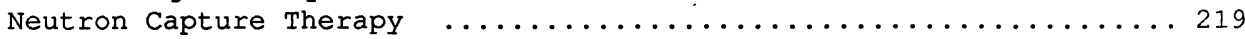

Y Yamamoto, H Nemoto, T Seko, S Takamatsu, F G Rong

Synthesis and Properties of Tetrakis-Carborane-Carboxylate Esters of 2,4-bis-(alpha, beta-dihydroxyethyl) Deuteroporphyrin IX

S B Kahl, M-S Koo

Carborane Compounds for Neutron Capture Therapy of Malignant Melanoma

J G Wilson

Synthesis of ${ }^{10} \mathrm{~B}$-and ${ }^{157} \mathrm{Gd}$-Labelled DNA Ligands for Neutron Capture Therapy $\ldots \ldots \ldots \ldots \ldots \ldots \ldots$

A D Whittaker, D P Kelly, M Pardee, R F Martin 
Behaviour of the Biologically Active Sulfhydryl Group of

Mercaptoundecahydro-Closo-Dodecaborate (2-) (mercaptoborate)

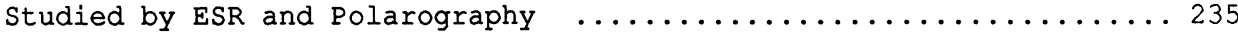

o Strouf, P Stopka, J Velická, S Bendárova, J Krupicka, F Jelen,

E Palecek, L Serak

Synthesis and Biological Properties of Boronated Thioureas

as Highly Selective Tumor Seekers for Melanoma .............239

W Tjarks, H Ketz, D Gabel

BORON CHWMISTRY - BPA

Complex Formation of Phenylboronic Acid Derivatives

with Aldo-Pentoses and Oligo-Saccharides ............... 243

Y Kinoshita, K Yoshino, Y Mori, H Kakihana, Y Mishima

Optical Purity Determination of $\mathrm{D}, \mathrm{L}-\mathrm{p}$-Boronophenylalanine by High Performance Liquid Chromatography with a Chiral

Mobile Phase ................................ 247

A K Gianotto, W F Bauer

Enantioselective Synthesis of $\mathrm{L}-(-)-4$-Boronophenylalanine

( $L-B P A)$ by Asymmetric Catalytic Hydrogenation

E G Samsel, B M Simpson

Complete Separation of Racemic p-Boronophenylalanine

by High Performance Liquid Chromatography with

Crown Ether-Coated Reversed-Phase Packings ................ 255

K Yoshino, S Mieda, T Maruyama, Y Mori, Y Mishima, M Ichihashi

\section{BORON MACROMOLECULES}

Liposomal Delivery of Boron for BNCT

K Shelly, M F Hawthorne, P G Schmidt

Delivery of Boron-10 for Neutron Capture Therapy by Means of Monoclonal Antibodies - Starburst Dendrimer

Immunoconjugates

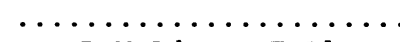

R F Barth, A H Soloway, D M Adams, F Alam,

Antibody Targetting of Boron Compounds

V A Ferro, J H Morris, W H Stimson

Application of Boronated Anti-CEA Immunoliposome to Boron Neutron Capture Therapy

H Yanagie, Y Fujii, T Tomita, Takahashi, H Nariuchi, M Sekiguchi, H Kobayashi

Studies Related to Antibody-Mediated Boron Delivery for

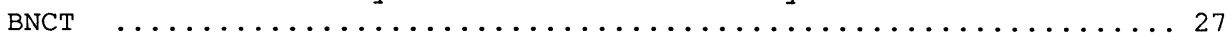

M F Hawthorne, A Varadarajan, R J Paxton, B G Beatty, F L Curtis

\section{BORON ANALYSIS IN BIOLOGICAL SAMPLES}

Continuous Measurement of ${ }^{10} \mathrm{~B}$ Concentration in Rabbit Brain Tissue and Blood using Prompt Gamma

Ray spectrometry ............................ 28

Y Nakagawa, T Kobayashi, Y Ueno, H Hatanaka, K Mukai, K Matsumoto 
Bioanalytical Investigations on Experimental BNCT with

Cold Neutrons at the Julich Research Reactor FRJ-2,

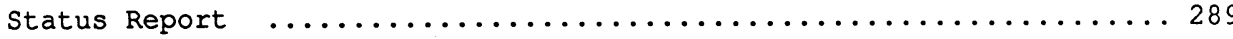

M Papaspyrou, I E Feinendegen

Boron Concentration Measurements for the Petten BNCT Project

M Konijnenberg, I Stecher-Rasmussen, C P J Raaymakers,

R Huiskamp, R I Moss, A C Begg, L Dewit, V G A Gregoire, B J Mijnheer

Flow Injection for Sample Introduction into Inductively Coupled Plasmas for the Determination of Boron in

Biological Samples. ............................... 297

W F Bauer, J W Wishard, C Rae, N Lassahn

Boron-10 Prompt Gamma Analysis Using a Diffracted Neutron Beam. .......301

$\mathrm{R}$ Rogus, O K Harling, I Olmez, S Wirdzek

Determination of Boron Concentration by Means of Direct Current

Plasma-Atomic Emission Spectroscopy

R F Barth, A H Soloway, D M Adams, F Alam, A K M Anisuzzaman

Rapid Spectrophotometric Determination of Boron in Biological Tissue with Alkali Fusion Decomposition

K Yoshino, C Nishio, E Ubukata, T Maruyama, Y Mori,

Y Mishima, C Honda, M Shiono, N Wadabayashi,

M Ichihashi, T Kobayashi, K Kanda

Phantom Experiment and Calculation for In Vivo ${ }^{10} \mathrm{~B}$

Analysis by Prompt Gamma-Ray Spectroscopy at

the Musashi Reactor

T Matsumoto, O Aizawa

Determination of Boron Concentration in Tissues by Means

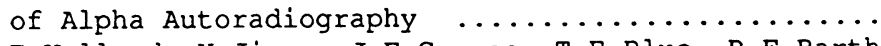

J E Wollard, Y Jiang, J F Curran, T E Blue, R F Barth

\section{BORON IMAGING - IN VITRO AND IN VIVO}

A New Boron MRI Method for Imaging BNCT Agents In Vivo .......... 321

G W Kabalka, Q C Cheng, P Bendel, D N Slatkin, P L Micca

In-Vivo Pharmacokinetic Evaluation of Boron Compounds Using Magnetic Resonance Spectroscopy and Imaging

K M Bradshaw, T L Richards, S L Kraft

Intracellular Boron Uptake and Distribution of $\mathrm{BSH}$ and BPA Determined Using Ion Microscopy

$\mathrm{X}$ Zha, B D Bennett, W A Ausserer, G H Morrison

Uptake of Boronated Monoclonal Antibodies by Melanoma Cells Visualised by Track Etch Autoradiography and

Electron Energy Loss Spectroscopy

D E Moore, J R Stretch, A.L Dawes, D J H Cockayne, B J Allen,

G Constantine

Interaction Between Boron Containing Compounds and Serum

Albumin Observed by Nuclear Magnetic Resonance

W F Bauer, K M Bradshaw, T L Richards 
The Necessity of Stochastic Radiobiology in BNCT, or, what is the RBE of the ${ }^{10} \mathrm{~B}(n, \alpha){ }^{7} \mathrm{~L} i$ Reaction?

D Gabel, V P Bond, J Kalef-Ezra, R G Fairchild

Enhancement of Thermal Neutron Induced Killing Effect on HeLa Cells Containing Boron-10 Nucleic Acid

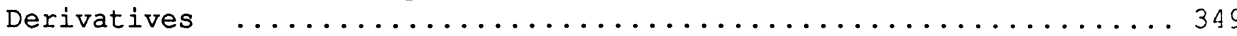

Y Ujeno, M Akaboshi, K Akuta, T Maki, K Kawai, Y Yamamoto

Further in Vitro Radiobiological Analysis on ${ }^{10} \mathrm{~B}-\mathrm{BPA}$ BNCT of Malignant Melanoma: Correlation of Determined ${ }^{10} \mathrm{~B}$-content and Cell Killing Effect

M Ichihashi, M Shiono, K Yamamura, A Komura, Y Mishima, K Yoshino, T Kobayashi, K Kanda, H Fukuda, Y Hori

${ }^{157} \mathrm{Gd}-\mathrm{Neutron}$ Capture: Potential of ${ }^{157} \mathrm{Gd}$-Labelled DNA

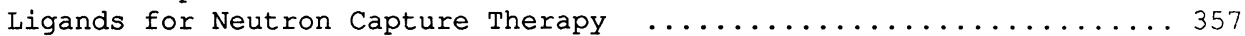

R F Martin, A Haigh, C Monger, M Pardee, A D Whittaker, D P Kelly, B J Allen

Gadolinium-Neutron Capture Reactions: A Radiobiological Assay ....... 361

Y Akine, N Tokita, T Matsumoto, H Oyama, O Aizawa

In Vitro Biological Efficacy of Boronat- $\lambda$ Tow Density Lipoproteins for NCT

S B Kahl, D Pate, B H Laster, E A Popenoe, R G Fairchild

In Vitro Incorporation of Boronophenylalanine by Amelanotic and Melanotic Murine and Human Malignant

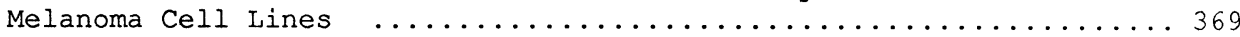

J K Brown, B J Allen, J E Chapman, M H Mountford, P Parsons

Studies on the Uptake of Para-Boronophenylalanine

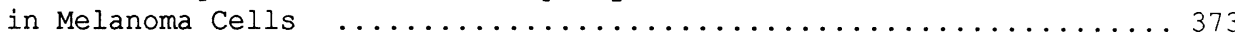

M Papageorges, C A Elstad, G G Meadows, P R Gavin, R D Sande, W F Bauer

Studies to use Fission Neutrons in BNCT for Deeper

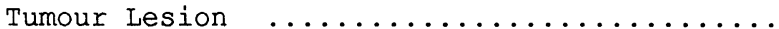

T Kadosawa, M Nakaichi, T Kawasaki, A Takeuchi, $\mathrm{T}$ Matsumoto, H Wakabayashi

Intracellular Distribution of Various Boron Compounds

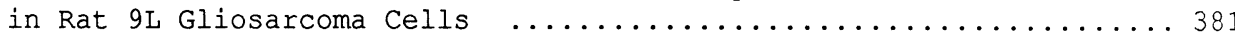

T Nguyen, B A Teicher, M Miura, S B Kahl, G L Brownell

In Vitro Evaluation of ${ }^{10} \mathrm{~B}-\mathrm{BPA}$ for Melanoma at Moata Joint Work Between Japan and Australia BNCT Research Teams

M Ichihashi, H Fukuda, J K Brown, M H Mountford, B J Allen, J G Wilson, Y Mishima

Thermal Neutron Capture Therapy Using ${ }^{10} \mathrm{~B}$-Conjugated Antimelanoma Antibodies: Quantification of

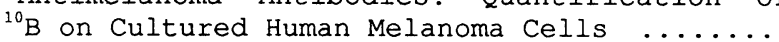

A Komura, T Nakagawa, M Ichihashi, Y Mishima

Ultrastructural Changes in Tumour Cells Following Boron Neutron Capture Therapy

D H Barkla, J K Brown, H Meriaty, B J Allen 
Dose modification by Neutron Capture in Cell Culture Using a $1 \mathrm{MeV}$ Mean Energy Fission Neutron Beam

W Sauerwein, H Szypniewski, F Poller, R Huiskamp

Thermal Neutron Induced Decomposition and Inactivation of Several Biomolecules

M Akaboshi, K Kawai, H Maki, K Akuta, Y Ujeno

Killing Effects of Gadolinium Neutron Capture Reaction

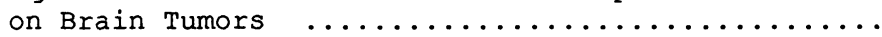

M Takagaki, Y Oda, S Miyatake, H Kikuchi, T Kobayashi, K Kanda, Y Ujeno, H Hatanaka

\section{PRECLINICAI ANIMAL STUDIES}

Spontaneous Canine Oral Melanoma: a Large Animal Model for BNCT

P R Gavin, S L Kraft, C E DeHaan, R D Sande, M Papageorges, W F Bauer

Dose-Response Analysis for Boron Neutron Capture Therapy of B16 Murine Melanoma Using p-Boronophenylalanine

J A Coderre, P L Micca, D N Slatkin, M S Makar

Increased Selective ${ }^{10} \mathrm{~B}$-Uptake by Malignant Melanoma Using Systemic Administration of ${ }^{10} \mathrm{~B}_{1}-\mathrm{BPA}$ Fructose Complex

C Honda, M Shiono, $N$ Wadabayashi, M Ichihashi, Y Mishima, T Kobayashi, K Kanda, Y Hori, K Yoshino

Local Control of Murine Melanoma Xenografts in Nude Mice by Neutron Capture Therapy .......................... 425

B J Allen, S Corderoy-Buck, D E Moore, Y Mishima, M Ichihashi

A Rat Model for the Treatment of Melanoma Metastatic to the Brain by Means of Neutron Capture Therapy

K Z Matalka, M Q Bailey, R F Barth, A E Staubus, D M Adams, A H Soloway, S M James, J H Goodman, J A Coderre, R G Eairchild, E K Rofstad

Radiobiology of Boron Neutron Capture Therapy: Problems With the Concept of Relative Biological Effectiveness

J A Coderre, M S Makar

In Vivo Cellular Pharmacology on the Selective Affinity of ${ }^{10} \mathrm{~B}_{1}-\mathrm{BPA}$ For Malignant Melanoma

M Shiono, T Shibata, C Honda, N Wadabayashi, M Ichihashi, Y Hori, K Yoshino, Y Mishima

Comparative Pharmacokinetics and Distribution Studies of Boric Acid, L-BPA and BSH in Two Murine Tumour Models

V G Gregoire, R Huiskamp, R Verijk, A C Begg

Evaluation of Response of Hepatocytes (in vivo) to Thermal Neutron Irradiation by Micronucleus Assay

K Akuta, K Ono, T Kobayashi, M Akaboshi, Y Ujeno, M Abe

Liposomes as Carriers of Boronated Thiouracils for NCT of

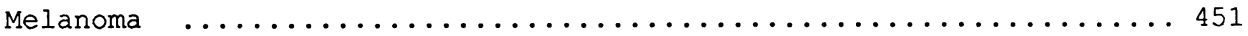

D E Moore, A K Chandler, S Corderoy-Buck, J G Wilson, $B \mathrm{~J}$ Allen 
Biodistribution, Toxicity and Efficacy of a Boronated

Porphyrin for Boron Neutron Capture Therapy

M Miura, P Micca, D Gabel, R Fairchild, D Slatkin

Basic studies in BNCT - Tolerance to Heavy Water

T Kadosawa, M Nakaichi, A Takeuchi, H Hatanaka

Boron Neutron Capture Therapy of Ocular Melanoma and

Intracranial Glioma Using p-Boronophenylalanine

J A Coderre, S Packer, D Greenberg, P L Micca, D D Joel,

S Saraf

A Quantitative Study on Pharmacokinetics and

Biodistribution of $\mathrm{BSH}$ in a Rat Glioma Model

R J B Hemler, C P Ceberg, A Brun, D Gabel,

B Larsson, B R R Persson, I G Salford

Biodistributions and Pharmacokinetics of p-Boronophenylalanine in C57BL/6 mice with GL261

Intracerebral Tumors, and Survival Following

Neutron Capture Therapy

G Solares, R Zamenhof, S Saris, D Wazer, S Kerley, $M$ Joyce, $H$ Madoc-Jones, L Adelman, O Harling

A large Animal Model for Boron Neutron Capture Therapy

P R Gavin, S L Kraft, C E DeHaan, M L Griebenow, M P Moore

Radiobiology Studies at Petten: Status on Cell Culture, Mice and Dog Experiments ........................ 485

R Huiskamp, A C Begg, V G A Gregoire, R Verrijk, D Gabel, A Siefert, R L Moss

The Biodistribution of Boron in Normal Canine Tissues Following Borocaptate Sodium Administration and the

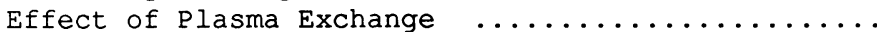

S L Kraft, P R Gavin, C E DeHaan, W F Bauer, T E Ary

Distribution of a Boronated Porphyrin (BTPP) in Osteosarcoma Bearing Nude Mice .............................4493

A Takeuchi, N Ojima, T Kadosawa, H Hatanaka

Feasibility Study of Boron Neutron Capture Therapy for Inoperable Liver Cancers ............................497

D Chiaraviglio, A Zonta, G Rescigno, C Cuzzoni, L Calamita, A Clerici, T Pinelli, F Fossati,

S Altieri, A Perotti, C Minoia, E Capelli, H Rief, R Ricchena, G Bottiroli, A C Croce

Tumour Localisation of Boronated Porphyrins in an Intracerebral Model of Glioma

J S Hill, S B Kahl, A H Kaye, M F Gonzales,

N J Vardaxis, C I Johnson, S S Stylli, Y Nakamura

ACUTE AND IATE EFFECTS IN NORMAL TISSUES

Acute and Late Reactions Following Boron Neutron Capture Epithermal-Neutron Therapy in Dogs with Spontaneous brain tumors ............................... 507

P R Gavin, C E DeHaan, S L Kraft, M P Moore, $\mathrm{L} R$ Wendling, $\mathrm{R} V$ Dorn III 
Tolerance Limits of the Normal Skin Treated by a Single

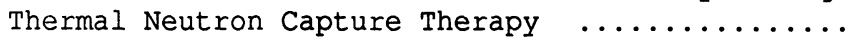

H Fukuda, K Ando, C Honda, M Ichihashi, Y Mishima,

J Hiratsuka, T Kobayashi, K. Kanda

Qualitative Dose Response of the Normal Canine Head to Epithermal Neutron Irradiation With and Without

boron capture .............................. 515

C E DeHaan, P R Gavin, S L Kraft, $\mathrm{F}$ J Wheeler, C A Atkinson

Boron Neutron Capture Therapy: The Radiation Response

of Rat skin and spinal Cord........................ 521

G M Morris, J W Hopewell

Influence of BNCT Radiations, on the Blood-Brain Barrier in

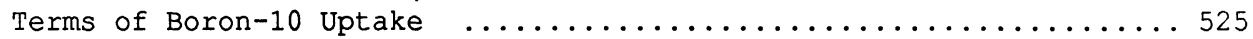

Y Nakagawa, T Kobayashi, Y Ueno, H Hatanaka, M Moritani, K Mukai, K Matsumoto

Blood-Brain Barrier and its Manipulation: Implications

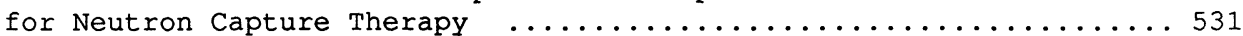

M K Gumerlock

The Biodistribution of Boron in Canine Spontaneous Intracranial Tumors Following Borocaptate Sodium

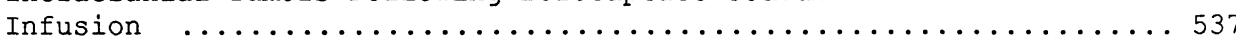

S I Kraft, P R Gavin, C E DeHaan, C W Leathers, $W F$ Bauer, $R$ V Dorn III

Regional and Total Body Dose Following BNCT Epithermal Head Irradiation: Biologic and Dosimetric Evaluation ................................ 541

P R Gavin, C E DeHaan, S L Kraft, Y D Harker, P D Randolph, $F$ J Wheeler

\section{BORON BIODISTRIBUTIONS IN GLIOMA PATIENTS}

Biodistribution of Boron Sulfhydryl (BSH) in Humans:

A Quality Control of Analytical Methods ................. 545

G Stragliotto, P Zbinden, O Pettersson, H Fankhauser

Pharmacokinetics of Boron Sulfhydryl (BSH) in Patients with Intracranial Tumors ........................ 549

G Stragliotto, A Munafo, J Biollaz, H Fankhauser

Biodistribution of Boron Sulfhydral (BSH) in Patients with

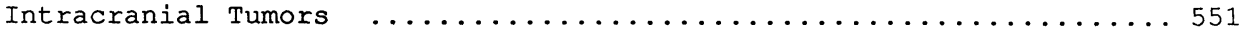

G Stragliotto, H Fankhauser

The Biodistribution of $\mathrm{BSH}$ in Patients with Malignant Glioma ....... 557

D Haritz, K Piscol, D Gabel

\section{CLINICAL STUDIES OF CANCERS WITH POOR PROGNOSES}

Clinical Results of Boron Neutron Capture Therapy ............. 561 H Hatanaka, K Sano, H Yasukochi

Clinical Experience of BNCT for Brain Tumours at Japan Atomic Energy Research Institute ................. 569

E Sirai, H Takahashi, M Issiki, K Arigane, M Iwaya, $\mathrm{H}$ Hatanaka, Y Hayakawa, Y Nakagawa 
Advances in the Control of Human Cutaneous Primary and Metastatic Melanoma by Thermal Neutron Capture Therapy

Y Mishima, M Ichihashi, C Honda, M Shiona, T Nakagawa,

H Obara, J Shirakawa, J Hiratsuka, K Kanda,

T Kobayashi, T Nozaki, O Aizawa, T Sato, H Karashima,

K Yoshino, H Fukuda

A proposal for Clinical Pilot Studies for Boron Neutron

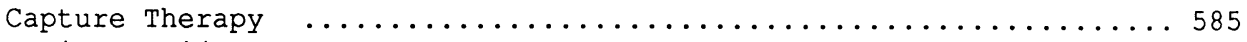

I Dewit, B Mijnheer, R Moss, D Gabel

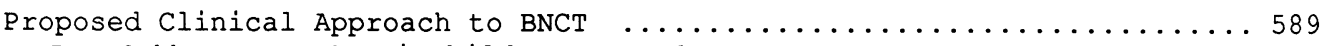

R A Gahbauer, R G Fairchild, J H Goodman, T E Blue

Clinical Experience of BNCT for Brain and Skin Tumours

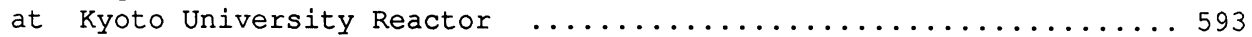

Y Ujeno, K Akuta, H Hatanaka, Y Mishima, Y Oda, Y Nakagawa

The State of the Art for Radiotherapy for Brain Tumours:

Non-Conventional Fractionation, Heavy Ions and Fast

Neutron Therapy ............................. 597

$\mathrm{R} V$ Dorn III

Incidence and Survival of Cancers for which Available

Treatments Appear Ineffective ..................... 605

D Shugg, M Jones, T Dwyer, A Bonnet, A Roberts

Limitations in the Conventional Treatment of Cerebral

Metastases from Melanoma ........................6 609

G Stevens

Photodynamic Therapy of Brain Tumours $\ldots \ldots \ldots \ldots \ldots \ldots \ldots \ldots \ldots$

A H Kaye

Cf-252 Neutron Brachytherapy, Neutron Capture Therapy

and Teletherapy for Melanoma and Malignant Gliomas............619

Y Maruyama, J Wierzbicki

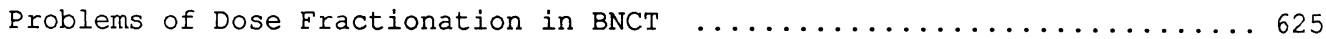

$\mathrm{H}$ R Withers

ROUND TABLE REVIEW OF NEUTRON CAPTURE THERAPY - THE CLINICIAN'S POINT OF

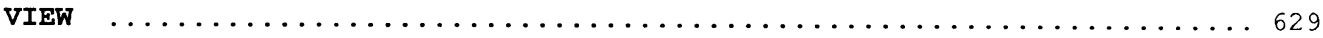

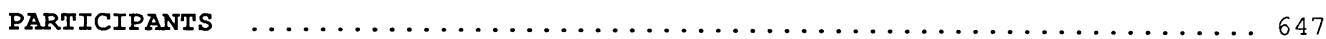

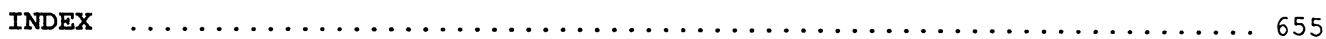

